\title{
Mineralization Reaction of Bacteria in Cement Materials
}

\author{
Chung-Hao Wu, a , Pang-Hsu Tai ${ }^{2, b}$ and How-Ji Chen ${ }^{3, c}$ \\ ${ }^{1}$ Department of Civil Engineering, Chienkuo Technology University, Taiwan \\ 2Department of Civil Engineering, National Chung Hsing University, Taiwan \\ achw@ctu.edu.tw, broberttai71@gmail.com, chojichen@nchu.edu.tw
}

Keywords: Bacillus pasteurii bacteria, Microbial induced calcium carbonate precipitation (MICP), Strength of mortar

Abstract. This paper examines how feasible it is to utilize microbial induced calcium carbonate precipitation (MICP) occasioned by Bacillus pasteurii (B. pasteurii) to fill pores and cracks within mortar and thus increase the strength and consequent durability of mortar. In this study, different mortars were prepared with a fixed water-cement ratio of 0.4 and addition of the B. pasteurii bacteria, urea and various contents of calcium nitrate, and their 3, 7, 14 and 28-day compressive strengths were measured for comparative analysis. The test results showed that the strengths of the mortars indeed significantly increased due to the effect of MICP. The results preliminarily prove the effect of MICP that fills pores in the mortars and thus increases their strengths; and also demonstrate that the bacteria can have the reaction of MICP using the calcium hydroxide generated from cement hydration in the mortars as a calcium source.

\section{Introduction}

Generation of pores and micro-cracks is inevitable within concrete. The appearance of continuous pores and micro-cracks etc. can accelerate infiltration of moisture or harmful substances into concrete and thus diminish its durability and strength. Many researchers have already sought to improve this by adding pharmaceutical agents; however, the chemical substances and ingredients in these additives are mostly not environmentally friendly. In the age of environmentalism, how to utilize the existing microbial technology in the nature to enable self-healing of concrete for self-repair has become a hot research topic [1-4].

Microbial mineralization is the process by which microorganisms produce ammonium and carbonate ions through their metabolism that breaks down urea. When these carbonate ions react with external calcium ions, calcium carbonate precipitation occurs. This is called microbial induced calcium carbonate precipitation (MICP). There are now already large numbers of papers and studies that have sought to fix cracks within concrete and enhance loading strength of soil based on this theory [3-6].

In this study, the B. pasteurii bacteria were mixed into mortars to see whether the MICP occasioned by them can generate calcium carbonate precipitation that fills cracks within the mortars and thus increases their strengths. 


\section{Test Program}

The water-cement ratio for mortars was fixed at 0.4. Group A was the control group, with typical mortars. In Group B, merely a liquid bacterial culture and a reagent solution were added to each mortar. In Group C, the same liquid bacterial culture and reagent solution in equal amounts plus a calcium source were added to each mortar. In Group D, the same liquid bacterial culture and reagent solution in equal amount plus the same calcium source in the doubled amount were added to each mortar. Addition of the calcium source was for the purpose of understanding how it might accelerate the reaction of MICP. Calcium nitrite $\left(\mathrm{Ca}\left(\mathrm{NO}_{3}\right)_{2}\right)$ was selected as the calcium source. The ingredient ratios in the different mortars are shown in Table 1 . The mortars were solidified into $5 \mathrm{~cm}$ $\times 5 \mathrm{~cm} \times 5 \mathrm{~cm}$ specimens for measurement of their 3, 7, 14 and 28-day compressive strengths. As the B. pasteurii bacteria were cultured in a liquid medium, the added liquid bacterial cultures were counted as part of the mixing water to prevent their addition from altering the fixed water-cement ratio for the mortars.

Table 1 Proportions of mortar $\left(\mathrm{kg} / \mathrm{m}^{3}\right)$

\begin{tabular}{|c|c|c|c|c|c|c|c|}
\hline W/C & type & Send & Cement & Water & Urea & $\mathrm{Ca}\left(\mathrm{NO}_{3}\right)_{2}$ & B.P. \\
\hline \multirow{4}{*}{0.4} & $0.4-\mathrm{A}$ & 1284 & 683 & 273 & 0.0 & 0.0 & 0.0 \\
\cline { 2 - 8 } & $0.4-\mathrm{B}$ & 1284 & 683 & 265 & 17.5 & 0.000 & 8.5 \\
\cline { 2 - 8 } & $0.4-\mathrm{C}$ & 1284 & 683 & 250 & 17.5 & 46.8 & 8.5 \\
\cline { 2 - 8 } & $0.4-\mathrm{D}$ & 1284 & 683 & 236 & 17.5 & 93.7 & 8.5 \\
\hline
\end{tabular}

\section{Analysis and Discussion}

The 3, 7, 14 and 28-day compressive strengths of the mortars are shown in Fig. 1, which reveals that the strengths of the mortars increase as the curing times increase. Differences between the specimens in the experimental groups, 0.4-B, 0.4-C and 0.4-D, and the control group 0.4-A are in the range of 58\% 113\%, as shown in Table 2. Except that the compressive strengths in Group B were higher than those in the control group, the remaining compressive strengths did not increase but declined. The 28 days curing strength in Group $\mathrm{C}$ with addition of the calcium source were conversely $2 \%$ lower than those in the control group probably due to the effect of calcium nitrite. Particularly in Group D, addition of excessive calcium nitrite caused the strengths to be significantly lower at merely $58 \% \sim 81 \%$ of those in the control group. 


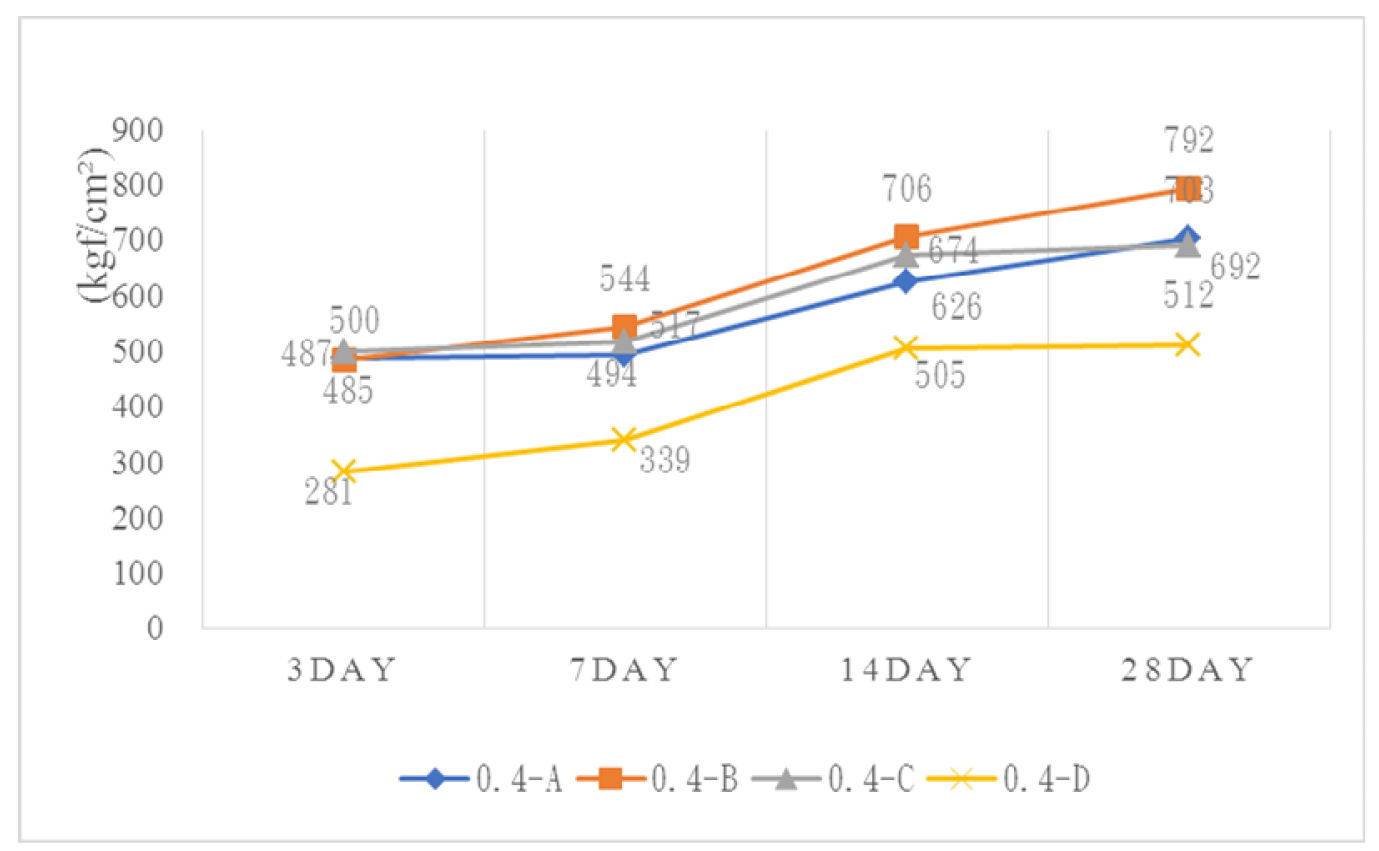

Figure 1 Compressive strengths in various curing days

Table 2 Compressive strength ratios in various mortars

\begin{tabular}{|c|c|c|c|c|}
\hline curing days & 3 day & 7 day & 14 day & 28 day \\
\hline $0.4-\mathrm{B} / 0.4-\mathrm{A}$ & $100 \%$ & $110 \%$ & $113 \%$ & $113 \%$ \\
\hline $0.4-\mathrm{C} / 0.4-\mathrm{A}$ & $103 \%$ & $105 \%$ & $108 \%$ & $98 \%$ \\
\hline $0.4-\mathrm{D} / 0.4-\mathrm{A}$ & $58 \%$ & $69 \%$ & $81 \%$ & $73 \%$ \\
\hline
\end{tabular}

Test results from Groups $\mathrm{C}$ and D show that addition of calcium nitrite as a calcium source is counterproductive to MICP in the mortars. The fact that the compressive strengths in Group B are higher than those in Groups A, C and D. The result preliminarily proves that the calcium hydroxide generated from cement hydration in the mortars is sufficient to be a calcium source for the reaction of MICP to enhance the strengths of the mortars.

As the water-cement ratio of 0.4 is a low ratio, which leads to generation of fewer pores within the specimens, this enables MICP to fill these pores (case in Groups A). However, the relative small amounts of water used in the mortars lead to a high consistency of cement paste. Then, the rapid MICP in the case of adding the calcium source in excessive amounts (case in Groups D) leads to the formation of large amounts of calcium carbonate. The phenomenon of rapid concreting occurred and it was impossible compacted the specimens effectively, resulting in weaker phase in mortars and hence lower compressive strength values. 


\section{Conclusions}

In this study, the B. pasteurii bacteria were directly mixed into mortars. Based on the results of compressive strengths of mortars at different curing ages, the effect of MICP occasioned by the B. pasteurii bacteria was observed. By summing up the findings, the following conclusions are drawn:

1. MICP occasioned by the B. pasteurii bacteria indeed can produce the effect of filling internal pores and thus increasing the compressive strengths of the mortars. When the water-cement ratio is 0.4 , the compressive strengths of 28 days curing mortars are about $13 \%$ higher than those of control group.

2. When excessive amounts of Calcium nitrite are added as the calcium source, rapid MICP may occur and lead to the formation of large amounts of calcium carbonate within very short periods of time. This may cause rapid concreting in mortars and it was impossible to compact the specimens effectively, resulting in weaker phase in mortars and hence lower compressive strength values.

3. Test results preliminarily prove that the effect of MICP can fill pores within the mortars and thus increase their strengths. The results also demonstrate that the bacteria can have the reaction of MICP using the calcium hydroxide generated from cement hydration in the mortars as a calcium source without the need for adding any other calcium source.

\section{References}

[1] K. Naka, Y. Chujo, Control of Crystal Nucleation and Growth of Calcium Carbonate by Synthetic Substrates, Chem. Mater. 13(2001), 3245.

[2] Bang, S. S., Galinat, J. K., and Ramakrishnan, V. Calcite precipitation induced by polyurethane-immobilized Bacillus pasteurii. Enzyme and Microb. Technol. 28(2001), 404-409.

[3] Day, J. L., Ramakrishnan, V., and Bang, S. S. Microbiologically induced sealant for concrete crack remediation. Proceedings of the 16th Engineering Mechanics Conference, Seattle, WA. (2003).

[4] How-Ji Chen, Pang-Hsu Tai, Ching-Fang Peng and Ming-Der Yang, "Concrete crack rehabilitation using biological enzyme", Computers and Concrete, Vol. 19 (2017), No. 4, 413-417.

[5] Dick, J., De Windt, W., De Graef, B., et al. Bio-deposition of a calcium carbonate layer on degraded limestone by Bacillus species [J]. Biodegradation, 17(4): 357-367. (2006).

[6] Shashi B. Atla, Yi-Hsun Huang, James Yang, How-Ji Chen *, Yi-Hao Kuo, Chun-Mei Hsu, Wen-Chien Lee, Chien-Cheng Chen, Duen-Wei Hsu, Chien-Yen Chen *, "Hydrophobic Calcium Carbonate for Cement Surface” Crystals, Vol. 7 (2017), No. 371, 1-9. 